for: Chugai Pharmaceutical Co., LTD., Janssen Pharmaceutical K,K,, Shigeto Tohma: None declared

DOI: 10.1136/annrheumdis-2020-eular.1890

\section{SAT0125 ASSOCIATION BETWEEN CHANGE IN HEALTH ASSESSMENT QUESTIONNAIRE DISABILITY INDEX AND TREATMENT RESPONSE IN PATIENTS WITH RHEUMATOID ARTHRITIS IN TOCILIZUMAB CLINICAL TRIALS}

S. Unizony ${ }^{1}$, J. Dang ${ }^{2}$, J. Han ${ }^{2}$, M. Michalska ${ }^{2}$, J. H. Best ${ }^{2} .{ }^{1}$ Massachusetts General Hospital, Harvard Medical School, Boston, United States of America; ${ }^{2}$ Genentech, Inc., South San Francisco, United States of America

Background: The efficacy and safety of intravenous (IV) and subcutaneous (SC) tocilizumab (TCZ) in combination with conventional synthetic disease-modifying antirheumatic drugs (csDMARDs) and as monotherapy in patients with rheumatoid arthritis (RA) has been demonstrated in large clinical trials and real-world data studies. The Health Assessment Questionnaire Disability Index (HAQ-DI) is commonly used to assess physical function in patients with RA. While HAQ-DI outcomes at Week 24 in TCZ clinical trials have been reported, outcomes at Week 12 and results stratified by treatment response categories at Weeks 12 and 24 have not been previously described.

Objectives: To report the association between change in HAQ-DI from baseline to Weeks 12 and 24 and Disease Activity Score in 28 joints (DAS28) response categories in patients who received TCZ or comparators in TCZ clinical trials.

Methods: Data from patients with active RA who received TCZ or a comparator from 6 Phase III or IV TCZ-IV studies (OPTION [NCT00106548], RADIATE [NCT00106522], TOWARD [NCT00106574] LITHE [NCT00109408], ACT-RAY [NCT00810199] and ADACTA [NCT01119859]) and 1 Phase III TCZ-SC study (BREVACTA [NCT01232569]) were analyzed. Mean change in HAQ-DI score at Weeks 12 and 24 was assessed in patients stratified by DAS28 disease activity level (DAS28 < 2.6 [remission], DAS28 $\geq 2.6$ to $\leq 3.2$ [low disease activity; LDA], DAS28 $>3.2$ to $\leq 5.1$ [moderate disease activity; MDA], DAS28 $>5.1$ [high disease activity; HDA] at Weeks 12 and 24. The adjusted least squares mean (LSM) change from baseline was estimated using a mixed model with repeated measures, including region (North America vs non-North America), RA duration (> 2 years vs $\leq 2$ years), baseline HAQ-DI and DAS28, treatment, visit, visit by treatment and visit by baseline HAQ-DI.

Results: Data from 5051 patients were included. Across all studies, the mean duration of RA ranged from 6.3 to 12.6 years. At baseline, patients had severe RA with a mean DAS28 $\geq 6.3$; baseline HAQ-DI was $\geq 1.5$. At Week 12 , patients who achieved remission or LDA had greater improvements in HAQ-DI than those in MDA or HDA (Figure 1). Results were similar at Week 24 (Figure 2). Among patients who received TCZ and achieved remission or LDA, mean improvement in HAQ-DI was $\geq 0.65$ and $\geq 0.44$, respectively, at Week 12 (Figure 1) and $\geq$ 0.48 and $\geq 0.43$ at Week 24 (Figure 2). Mean changes in HAQ-DI were similar between patients who received TCZ-IV in combination with MTX or as monotherapy (ACT-RAY) and in those who received TCZ-IV or ADA as monotherapy (ADACTA).

Conclusion: Patients with long-standing, severe RA who received IV or SC TCZ as monotherapy or in combination with csDMARDs had improvement in physical function and disease activity at Week 12 that was maintained at Week 24. Overall, across all the trials, response to treatment was associated with improvement in physical function.

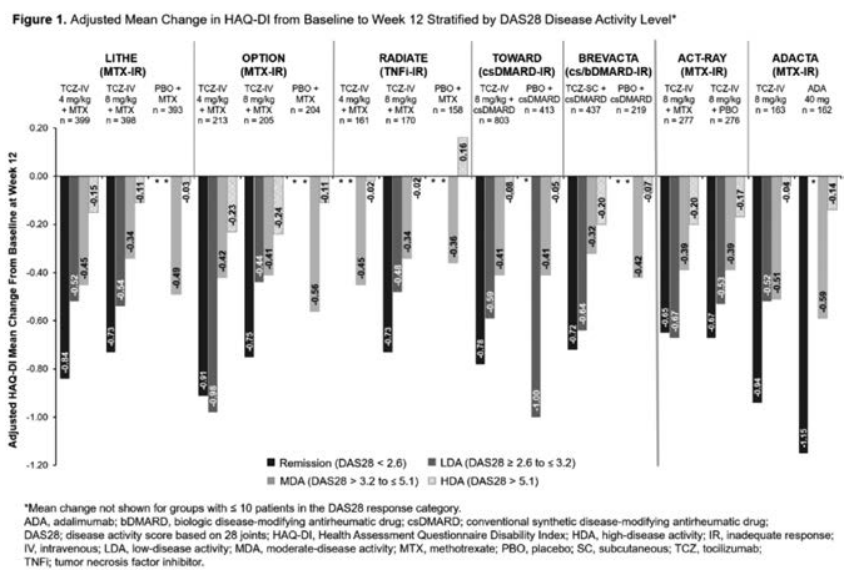

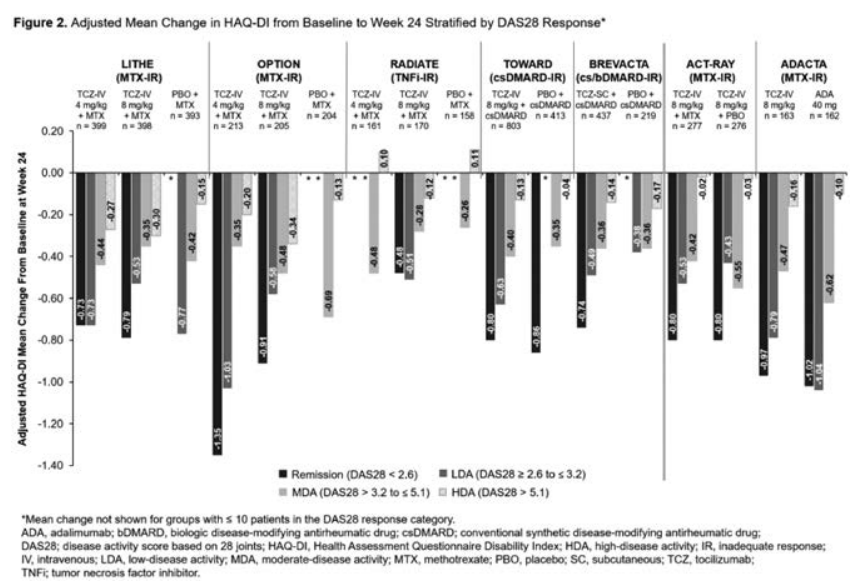

Acknowledgments : This study was sponsored by Genentech, Inc. Support for third-party writing assistance, furnished by Health Interactions, Inc, was provided by Genentech, Inc.

Disclosure of Interests: : Sebastian Unizony Grant/research support from: Genentech, Inc., Joseph Dang Shareholder of: Genentech, Inc., Employee of: Genentech, Inc., Jian Han Shareholder of: Genentech, Inc., Employee of: Genentech, Inc., Margaret Michalska Shareholder of: Genentech, Inc., Employee of: Genentech, Inc., Jennie H. Best Shareholder of: Genentech, Inc., Employee of: Genentech, Inc.

DOI: 10.1136/annrheumdis-2020-eular.614

\section{SAT0126 \\ BIOLOGICAL MANAGEMENT IN RHEUMATOID ARTHRITIS: RESULTS OF A REAL-WORLD COHORT FROM THE NETHERLANDS}

E. Van Mulligen ${ }^{1}$, S. Ahmed ${ }^{1}$, P. De Jong ${ }^{1} .{ }^{1}$ Erasmus University Medical Center, Rheumatology, Rotterdam, Netherlands

Background: Management of rheumatoid arthritis (RA) has improved dramatically due to early diagnosis, treat-to-target approaches based on disease activity measures, and the introduction of biological disease modifying anti-rheumatic drugs (bDMARDs). Tumor necrosis factor inhibitors (TNFis) are the most frequently prescribed bDMARDs after failure on conventional synthetic (cs)DMARDs. However, data on drug survival and predictors that influence the survival time are sparse. Moreover, drug survival could decrease with the number of bDMARDs that have been used.

Objectives: To investigate drug survival for first and second line biologicals and factors that influence survival time.

Methods: We used a retrospective observational cohort in which data were retrieved from the local pharmacy database and patient records of the Erasmus Medical Center in the Netherlands. We included patients who started with a TNF-inhibitor between 2000 and 2020 and were diagnosed with RA. Data on age, gender, disease duration, time to first biological, survival time, co-medication and reasons for discontinuation were collected.

Results: Data were already derived from 216 RA patients (table 1). Of the included patients $28(13 \%)$ started their first TNFi within 6 months after diagnosis, while 56 (26\%) patients started their first TNFi two years after diagnosis. Median $(95 \%)$ survival time of the first-line biological was 1.6 years (1-2), and for the second-line biological 0.8 years $(0.5-0.9)$. Biological survival was significantly longer for the first-line biological compared to the second $(p=0.0008)$ (Figure $1 A)$. Discontinuation reasons for the first-line biological were ineffectiveness (38\%), adverse events $(13 \%)$, remission $(18 \%)$, pregnancy $(17 \%)$, patient preference $(4 \%)$ or other reasons $(10 \%)$. Discontinuation reasons for the second-line biological were ineffectiveness $(51 \%)$, adverse events $(17 \%)$, remission $(7 \%)$, pregnancy (13\%), patient preference $(2 \%)$ or other reasons $(10 \%)$ (table 1). Drug survival for the first-line biological was significantly longer when it was combined with a csDMARD $(p=0.05)$ (Figure 1B). Furthermore, multivariable cox regression analyses showed a significant relation between first-line biological survival time and gender $(p=0.005$, hazard ratio $0.28(95 \% \mathrm{Cl} 0.12-0.68))$ and erosions $(\mathrm{p}=0.004$, hazard ratio 0.37 (95\% $\mathrm{Cl} 0.19-0.73)$ ) when discontinuation due to remission was omitted from the analysis. Within aforementioned analyses we corrected for ACPA, age of diagnosis, age at first biological, and BMI. The chance that patients stopped with their biological due to remission was negatively influenced by having erosions $(p=0.02$, hazard ratio $0.07(95 \% \mathrm{Cl} 0.007-0.66)$ ) and positively influenced by age at first biological $(\mathrm{p}=0.03$, hazard ratio $1.4(95 \% \mathrm{Cl} 1.03-1.94))$ in a multivariable cox model in which we corrected for gender, ACPA, erosions, BMI, and age of diagnosis. 